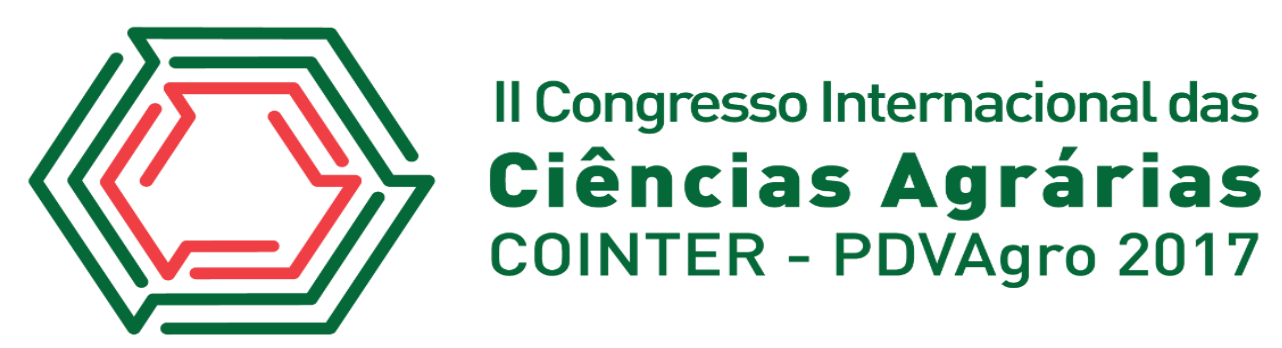

\title{
AVALIAÇAO MICROBIOLÓGICA DA CARNE BOVINA COM ADIÇÃO DE DIFERENTES CONCENTRAÇÕES DE ERVA-SAL (Atriplex nummularia)
}

\author{
Apresentação: Pôster \\ Uri Vanille Raiol da Silva ${ }^{1}$, Luiz Leodécio Monteiro Alves Junior ${ }^{2}$, Maria Carla da Silva Campêlo ${ }^{3}$, \\ Lucas de Oliveira Soares Rebouças ${ }^{4}$, Patrícia de Oliveira Lima ${ }^{5}$

\footnotetext{
${ }^{1}$ Mestranda do programa de pós-graduação em produção animal - UFERSA, Mossoró- RN, Brasil; ${ }^{2}$ Zootecnista- UFERSA, Mossoró-RN, Brasil; ${ }^{3}$ Mestre em ciência animal - UFERSA, Mossoró- RN, Brasil; ${ }^{4}$ Mestre em produção animal- UFERSA, Mossoró-RN, Brasil; ${ }^{5}$ Docente associado I (CCA/DCAN) Universidade Federal Rural do Semi-Árido-UFERSA, Mossoró-RN, Brasil
}

\section{Introdução}

A carne bovina é um alimento de elevada densidade nutricional e que apresenta uma expressiva participação na dieta humana, sendo uma das proteínas mais consumidas entre os brasileiros, estando entre os alimentos padrão da dieta básica da maioria da população (SOUZA et al., 2013). Alguns fatores são cruciais para manter o crescimento do mercado da carne bovina no Brasil e no mundo, entre os principais está a qualidade do produto, principalmente a higiênicosanitária. A carga microbiana presente na carne bovina in natura é favorecida por fatores como raça e saúde do animal vivo, condições antes e durante o abate, resfriamento da carcaça, condições sanitárias de manuseio, tipo de embalagem e condições de distribuição e estocagem. $\mathrm{O}$ alto teor de nutrientes, a elevada atividade de água e o pH próximo à neutralidade podem favorecer o desenvolvimento de microrganismos contaminantes, originários do próprio animal ou de fontes externas (ORDÓÑEZ et al., 2005; BRIDI\&CONSTANTINO, 2009).

Os conservantes mais utilizados atualmente são os aditivos sintéticos ou aditivos químicos, no entanto, pesquisas indicam que o consumo diário produz reações maléficas à saúde do consumidor, tais como alergias, alterações no comportamento, carcinomas e outros (ALBUQUERQUE et al., 2012). Deste modo, as indústrias de carnes estão buscando substituir os atuais condimentos e conservantes sintéticos por conservantes naturais, que não possuem efeitos nocivose não afetam a vida de prateleira dos produtos.

Utilizada no semiárido, principalmente como fonte de alimentação para animais ruminantes, a erva-sal (Atriplex nummularia) apresenta um potencial para ser usada na conservação da carne bovina, devido à significante quantidade de sais presente nos seus tecidos e sua viabilidade interessante,podendo ser testada como condimento natural na carne bovina durante seu tempo de 
prateleira. (PORTO et. al., 2000; CARVALHO et. al., 2015). Diante disso, objetivou-se avaliar o potencial da utilização da erva-sal como conservante para carne bovina, analisando o efeito da planta sobre as microbiológicas da carne em tratamento com diferentes quantidades da erva.

\section{Fundamentação Teórica}

A tecnologia de alimentos tem impulsionado o consumo de carne com ingredientes aditivos com o foco de favorecer a conservação desse produto e também melhorar as condições de nutrição da população, buscando oferecer aos consumidores, produtos com qualidades nutricionais, sensoriais e com maior tempo de conservação, com preços acessíveis a pessoas de todas as classes sociais (AMBIEL, 2004).

A necessidade do uso de aditivos naturais e atóxicos justifica o desenvolvimento de pesquisas que possam garantir a utilidade destes em substituição aos aditivos sintéticos para prevenir a deterioração dos alimentos, pois os aditivos sintéticos de alimentos são considerados seguros, mas a utilização deles encontra cada vez mais restrições pela regulamentação internacional (ZACARÃO, 2013).

A utilização de extratos naturais atuando como antimicrobianos tem sido uma boa alternativa para aqueles que buscam uma alimentação mais saudável. É justamente esse apelo por uma alimentação mais saudável que tem levado a busca da utilização de extratos de plantas naturais para atuar como antimicrobianos (ZACARÃO, 2013).

A particularidade da erva-sal em absorver teores consideráveis de sais através de seu sistema fisiológico podem inibir o desenvolvimento de microrganismos indesejáveis, alterando o $\mathrm{pH}$ e a pressão osmótica, inibindo o crescimento de bactérias (MORENO, 2011).

\section{Metodologia}

A presente pesquisa é caracterizada quanto a sua natureza como quantitativa do tipo experimental. Foi adquirida uma peça de carne bovina tipo lombo (Longissimus dorsi), oriunda de um frigorífico local do município de Mossoró/RN.

A carne foi cortada em amostras de $200 \mathrm{~g}$ e com aproximadamente $4 \mathrm{~cm}$ de espessura, e foram separadas em porções de acordo com os tratamentos. Sendo estes 0\% (carne sem adição de erva-sal); $1 \%$ (carne tratada com adição de 1\% de erva-sal); 2,5\% (carne tratada com adição de $2,5 \%$ de erva-sal) e $5 \%$ (carne tratada com adição de 5\% de erva-sal). 
As carnes foram acondicionadas em bandejas de poliestireno isoladas com plástico filme de PVC e armazenadas em temperatura de refrigeração $\left(4^{\circ} \mathrm{C} \pm 1^{\circ}\right)$. As análises foram realizadas durante o período de armazenamento, nos dias: 0, 1, 3, 6, 9 e 12 .

A avaliação microbiológica foi realizada no Laboratório de Inspeção de Produtos de Origem Animal (LIPOA) da Universidade Federal Rural do Semiárido (UFERSA), onde foi pesado (25g) da carne de forma asséptica e transferidas para sacos plásticos estéreis, onde foram acrescidos $225 \mathrm{~mL}$ de água peptonada tamponada estéril para posterior homogeneização em "Stomacher" durante 2 minutos, obtendo-se assim a diluição $10^{-1}$, a partir da qual foram obtidas as demais diluições decimais até $10^{-6}$. Após a diluição, as amostras foram submetidas às técnicas para determinação da contagem total de psicrotróficas, bactérias aeróbias mesófilas e Salmonella sp. Utilizando a metodologia oficial brasileira para análises microbiológicas de alimentos (MAPA, 2003). Os resultados foram expressos em (UFC/g).

Os dados foram submetidos à análise de variância e teste de comparação de médias. Os efeitos dos diferentes tratamentos sobre cada variável foram comparados por meio do teste de Tukey.

\section{Resultados e Discussões}

Quando verificado o desenvolvimento de bactérias aeróbias mesófilas, notou-se, desde o dia zero de armazenamento, valores elevados de microrganismos avaliados, havendo diferença estatística $(\mathrm{P}<0,05)$ entre as amostras sem adição de erva-sal $(0 \%)$ e todos que receberam a erva, porém após o dia zero de armazenamento foi observado um número elevado desses microrganismos nos tratamentos controle $(0 \%)$ e com $5 \%$ de adição de erva-sal, com diminuição dos níveis de contaminação nos tratamentos com $1 \%$ e $2,5 \%$ de erva-sal a partir do dia 1 , como mostra a Tabela 1.

Tabela 1 - Contagem de microrganismos mesófilos na carne bovina com diferentes concentrações de erva-sal (Atriplex nummularia).

\begin{tabular}{lllllll}
\hline \multirow{2}{*}{$\begin{array}{c}\text { Dias de } \\
\text { armazenamento }\end{array}$} & Análises & \multicolumn{4}{c}{ Concentrações de erva sal } & \\
\cline { 3 - 5 } & & $0 \%$ & $1 \%$ & $2,50 \%$ & $5 \%$ & $\mathrm{CV}(\%)$ \\
\hline
\end{tabular}

\begin{tabular}{ccccccc}
0 & & $4,11 \mathrm{Bb}$ & $6,40 \mathrm{Aa}$ & $6,20 \mathrm{Aa}$ & $5,40 \mathrm{Ba}$ & \\
1 & Mesófilos & $6,40 \mathrm{Aa}$ & $5,28 \mathrm{Bb}$ & $6,00 \mathrm{Aa}$ & $6,40 \mathrm{Aa}$ & 1,14 \\
3 & $\left(\log _{10} \mathrm{UFC} / g\right)$ & $6,40 \mathrm{Aa}$ & $4,86 \mathrm{Bb}$ & $5,26 \mathrm{Bb}$ & $6,40 \mathrm{Aa}$ & \\
6 & $6,40 \mathrm{Aa}$ & $6,40 \mathrm{Aa}$ & $5,10 \mathrm{Bb}$ & $6,40 \mathrm{Aa}$ & \\
\cline { 2 - 4 } & &
\end{tabular}


Foram ainda contabilizados microrganismos psicrotróficos (Tabela 2) desde o primeiro dia de armazenamento em todos os tratamentos. Havendo diferença entre os dias avaliados, com taxas de contaminação estatisticamente iguais $(\mathrm{P}>0,05)$. Nos tratamentos com 1 e 2,50\% da erva sal foi verificado uma diminuição dos microorganismos com o aumento dos dias.

Tabela 2 - Contagem de microrganismos psicrotróficos na carne bovina com diferentes concentrações de erva-sal (Atriplex nummularia).

\begin{tabular}{ccccccc}
\hline \multirow{2}{*}{$\begin{array}{c}\text { Dias de } \\
\text { armazenamento }\end{array}$} & Análises & \multicolumn{4}{c}{ Concentrações de erva sal } & \multirow{2}{*}{ CV (\%) } \\
\cline { 3 - 5 } & & & $1 \%$ & $2,50 \%$ & $5 \%$ & \\
\hline & & $5,60 \mathrm{Aa}$ & $6,43 \mathrm{Aa}$ & $6,23 \mathrm{Aa}$ & $6,40 \mathrm{Aa}$ & \\
1 & Psicrotróficos $_{0}$ & $6,40 \mathrm{Aa}$ & $5,85 \mathrm{Aa}$ & $5,79 \mathrm{Aa}$ & $5,92 \mathrm{Aa}$ & 2,04 \\
3 & $\left(\log _{10}\right.$ UFC/g) & $6,40 \mathrm{Aa}$ & $5,30 \mathrm{Ab}$ & $5,58 \mathrm{Ab}$ & $5,80 \mathrm{Aa}$ & \\
6 & & $6,40 \mathrm{Aa}$ & $6,40 \mathrm{Aa}$ & $6,40 \mathrm{Aa}$ & $6,40 \mathrm{Aa}$ & \\
\hline
\end{tabular}

Letras maiúsculas distintas na coluna e letras minúsculas distintas na linha indicam diferença entre as médias pelo teste Tukey $5 \%$.

Populações elevadas de microrganismos psicrotóficos e mesófilos revelam condições higiênico-sanitárias inadequadas, interferindo na qualidade da matéria-prima aliada a tempo e temperatura de estocagem (DE MARCHI et al., 2012).

Tais resultados sugerem que a carne bovina já apresentava valor elevado de microrganismos e a erva-sal, quando fora adicionada em forma de pó, apresentou efeito sobre o número de microrganismos somente nas quantidades de 1 e 2,50\%, com números decrescentes nos dias 1 e 3 de avaliação, não sendo capaz de impedir o crescimento destes microrganismos.

Observou-se ainda a ausência de Salmonella sp. nas amostras de carne, garantindo o padrão estabelecido pela legislação brasileira para alimentos comercializados, RDC n 12/2001 (BRASIL, 2001).

\section{Conclusões}

Nenhuma quantidade da erva-sal (Atriplex nummularia) usadas nos tratamentos desse estudo foi suficiente para impedir o total crescimento dos microrganismos presentes na carne no decorrer dos dias de armazenamento, porém as quantidades de 1 e 2,5\% causou uma redução dos microrganismos com o passar dos dias avaliados.

\section{Referências}


ALBUQUERQUE, M.V., SANTOS, S.D., CERQUEIRA, N.D.V., SILVA, J. D. Educação alimentar: uma proposta de redução do consumo de aditivos alimentares. Revista Química Nova na Escola, v. 34, n. 2, 2012.

AMBIEL, C. Efeitos das concentrações combinadas de cloreto e lactato de sódio na qualidade e conservação de um sucedâneo da carne-de-sol. 2004. 84f. Dissertação. Universidade Estadual de Campinas, Campinas.

BRASIL. Resolução-rdc $n^{\circ} 12$, de 02 de janeiro de 2001. Regulamento técnico sobre padrões microbiológicos para alimentos. ANVISA. Diário Oficial da União, Poder Executivo, Brasilia, DF, 02 jan. 2001. Disponível em: http://portal.anvisa.gov.br.

BRIDI, A.M.; CONSTANTINO, C.Qualidade e Avaliação de Carcaças e Carnes Bovinas. In: Congresso Paranaense dos Estudantes de Zootecnia, Anais... Maringá. 2009.

BRILHANTE, J. C. A. Contribuição de solutos orgânicos e inorgânicos no potencial osmótico de folhas de Atriplex nummularia submetidas ao $\mathrm{NaCl}$, seca e PEG. 2006. 195f. Dissertação (Mestrado em Agronomia-Fitotecnia) - Universidade Federal do Ceará, Fortaleza, 2006.

CARVAlHO, M. F., EL-DEIR, S. G., CORRÊA, M. M., CARVALHO, G. C. Estudo de caso de três espécies de plantas bioindicadoras de solos salinos. Revista Verde de Agroecologia e Desenvolvimento Sustentável, v. 10, n. 3, p. 01-08, 2015.

MORENO, G. M. B. Feno de erva-sal (Atriplex nummularia) na terminação de cordeiros Santa Inês. 2011. 120 f. Tese (Doutorado) - Curso de Zootecnia, Faculdade de Ciências Agrárias e Veterinárias, Universidade Estadual Paulista, Jaboticabal, 2011. OURIVES, Eliete Auxiliadora Assumpção.

ORDÓÑEZ, J.A. et al. Tecnologia de Alimentos: Alimentos de Origem Animal. 2. ed. Porto Alegre: Artmed, 2005. 275 p. 2 v.

PORTO, E.R.; ARAÚJO, G.G. Uso da erva sal (Atriplex nummularia) como forrageira irrigada com água salobra. Embrapa semi-árido. Circular técnica n. 53. Petrolina, PE, 2000.

SOUZA, A. M. et al. Alimentos mais consumidos no Brasil: Inquérito nacional de alimentação 2008-2009. Revista de Saúde Pública, v. 47, n. suppl. 1, p. 190-199, 2013.

ZACARÃO, P.C. Estudo da propriedade antimicrobiana dos óleos essenciais de alho (allium sativum), pimenta do reino (piper nigrum) e pimenta rosa (schinus molle) para aplicação em cortes de frango temperados. 